\title{
TAG QUESTIONS IN ENGLISH SPOKEN DISCOURSE: CORPUS-BASED LINGUISTIC AND PRAGMATIC ANALYSIS
}

\author{
Larisa A. Kochetova \\ Volgograd State University, Volgograd, Russia \\ Elena Yu. Ilyinova \\ Volgograd State University, Volgograd, Russia \\ Tatiana A. Klepikova \\ Saint Petersburg State University of Economics, Saint Petersburg, Russia
}

\begin{abstract}
Based on an integrative methodology that combines quantitative and qualitative methods of linguistic research, the authors consider grammatical forms, syntactic types and pragmatic functions of the tag question in British spoken discourse. The research material included samples of dialogues with tag questions taken from British contemporary fiction and the Spoken BNC2014. Drawing on the theory of linguistic metarepresentation and using corpus analysis tools the authors presented the model under study in structuralsyntactic and functional-pragmatic perspectives and obtained reliable data on discourse realization of tag question models, specified their standard and common usage polarity status, distinguished bi- and monopolarity variations. An analysis of the tag question types that are distinguished as the combinations of the predicative and auxiliary parts shows that the most frequent type of tag question is the one formed with an affirmative predicative part and a negative tag. The corpus-based approach allowed obtaining quantitative data on frequencies of tag questions in British spoken discourse, retrieving the repertoire of tag questions with their grammatical representation. It is shown that in the corpus under study the most frequent form of the tag question is the form isn't it?. The least frequent forms of tag questions are the ones formed with the have verb, as well as the modal verbs will, may, can, which supports the thesis that tag questions are losing ground in British spoken discourse. Discourse-pragmatic analysis of utterance contexts with tag questions highlighted its discourse value in the British tradition of conversation, as they perform the following communicative functions: informational; etiquette; interpersonal-relation-corrective (focus-positive or focus-negative).
\end{abstract}

Key words: corpus, corpus linguistics, spoken discourse, tag question, pragmatics, intention, communicative function.

Citation. Kochetova L.A., Ilyinova E.Yu., Klepikova T.A. Tag Questions in English Spoken Discourse: CorpusBased Linguistic and Pragmatic Analysis. Vestnik Volgogradskogo gosudarstvennogo universiteta. Seriya 2. Yazykoznanie [Science Journal of Volgograd State University. Linguistics], 2021, vol. 20, no. 5, pp. 67-86. (in Russian). DOI: https://doi.org/10.15688/jvolsu2.2021.5.6

\section{ЛИНГВОПРАГМАТИЧЕСКОЕ ИССЛЕДОВАНИЕ РАЗДЕЛИТЕЛЬНОГО ВОПРОСА В АНГЛОЯЗЫЧНОМ МЕЖЛИЧНОСТНОМ ОБЩЕНИИ: КОРПУСНЫЙ АНАЛИЗ}

\author{
Лариса Анатольевна Кочетова \\ Волгоградский государственный университет, г. Волгоград, Россия
}




\section{Елена Юрьевна Ильинова}

Волгоградский государственный университет, г. Волгоград, Россия

\section{Татьяна Альбертовна Клепикова}

Санкт-Петербургский государственный экономический университет, г. Санкт-Петербург, Россия

Аннотация. Основываясь на интегративной методологии, объединяющей количественные и качественные методы лингвистических исследований, авторы рассматривают грамматические формы, синтаксические типы и прагматические функции разделительного вопросительного высказывания в британской устной речи. Материалом исследования послужили фрагменты британского художественного дискурса, содержащие образцы современной диалогической речи с разделительным вопросом, и корпус устной британской речи BNC2014. Использование теории лингвистического метарепрезентирования и инструментов корпусного анализа при рассмотрении разделительного вопроса в структурносинтаксическом и функционально-прагматическом аспектах позволило получить достоверные данные о специфике реализации моделей разделительного вопроса, обосновать нормативно-узуальный статус (Т.А. Клепикова, Л.А. Кочетова), выявить варианты би- и монополярности их синтаксической структуры (Е.Ю. Ильинова). Результаты анализа моделей разделительных вопросов, выделяемых с учетом комбинаций предикативной и вспомогательной части, показали, что доминирует разделительный вопрос с утвердительной предикативной частью и отрицательным тэгом. С опорой на корпусные данные о языковых единицах и структурах Л.А. Кочетова выявила частоту употребления разделительного вопроса в британской устной разговорной речи, установила репертуар грамматических форм его реализации, представила данные о доминировании в позиции тэга формы isn 't it?, низкой частотности обращения к глаголу have, модальным глаголам will, may, can, тенденции к снижению роли разделительного вопроса в британском межличностном общении. Дискурсивно-прагматический анализ контекстов с разделительным вопросительным высказыванием позволил Е.Ю. Ильиновой обосновать дискурсивную ценность разделительного вопроса в британской традиции устной разговорной речи, отраженную в следующих коммуникативных функциях: информационная, этикетная, корректирующая межличностные отношения (фокусно-позитивная или фокусно-негативная).

Ключевые слова: корпус, корпусная лингвистика, устный дискурс, разделительный вопрос, прагматика, интенция, коммуникативная функция.

Цитирование. Кочетова Л. А., Ильинова Е. Ю., Клепикова Т. А. Лингвопрагматическое исследование разделительного вопроса в англоязычном межличностном общении: корпусный анализ // Вестник Волгоградского государственного университета. Серия 2, Языкознание. - 2021. - T. 20, № 5. - С. 67-86. - DOI: https:/ /doi.org/10.15688/jvolsu2.2021.5.6

\section{Введение}

В теории дискурса изучение особенностей речевого поведения ведется как с целью установления универсалий построения дискурса, так и с целью выявления этнокультурной специфики речевых предпочтений представителей разных языковых сообществ. При этом в современных работах по лингвистике доминирует коммуникативно-прагматический подход, когда исследователи идут от фактов использования языка в разных ситуациях и условиях общения, собирают коллекции примеров, анализируют их, опираясь на комплексные методики, а затем делают выводы о типологии и закономерностях речевой практики в границах отдельной социокультурной ситуации [Ирисханова, 2009; Карасик, 2017; Лари- на, 2013; Матвеева, Ленец, Петрова, 2013; Сорокина и др., 2019; Pearson, West, Turner, 2005; и др.]. В своих публикациях они обращаются к базовым единицам языка и речи, но, анализируя контексты их употребления, получают новые сведения о семантике и функциональной прагматике этих единиц. По нашему мнению, современная теория дискурса, допускающая осмысление языкового материала «через интерпретацию того, как люди понимают окружающий мир и выражают свое понимание при помощи языка» [Леонтович, 2011, с. 12], нуждается в интегративной методологии изучения реальных форм коммуникации. Она может базироваться на сочетании в рамках одного исследования количественных и качественных методов, которые выступают инструментами анализа продуктов реаль- 
ной дискурсивной практики [Клепикова, 2017]. Использование количественных методов в изучении коммуникативных процессов создает базу достоверных данных о языковых реализациях в границах отдельных форм дискурca, но на следующем этапе требуется проведение многопараметрического качественного анализа данных, учитывающего социальный контекст, сложную систему существующих в обществе взаимосвязей, отраженных в речевой практике, что позволит должным образом интерпретировать полученные количественные данные.

В современной дискурсивной лингвистике отмечаются тенденции слияния формально-структурного, лингвопрагматического, когнитивно-семантического и социокультурного подходов к изучению дискурса в его разных реализациях [Карасик, 2017] и активного применения методов корпусной лингвистики, внедряемых в исследования, посвященные анализу форм вербальных действий [Чернявская, 2017; 2018; Baker, 2006; 2012; Baker et al., 2008; Brezina, 2018; Cameron, 1997; Mautner, 2009; Partington, 2010; и др.]. Стремительное развитие корпусной лингвистики и формирование электронных корпусов текстов устной речи открывают возможности для получения объективных данных об общих и вариативных дискурсивных моделях в разных коммуникативных ситуациях и с учетом заданных исследователем социальных, прагматических, иных параметров, определяющих природу дискурса как «исторически сложившейся опосредованной языком формы социальной практики» [Историческая динамика..., 2017, с. 5]. Интеграция методологических основ корпусной лингвистики с принципами теории дискурса, основанная на сочетании количественных и качественных методов, помогает преодолеть противостояние между корпусной лингвистикой и анализом дискурса. Лингвисты, проводящие корпусные исследования, часто критикуют коллег за то, что те редко используют статистические инструменты для объективной характеристики изучаемого явления. Специалисты по теории дискурса в свою очередь считают, что корпусная лингвистика сосредоточена на изучении статистики отдельных групп слов и не учитывает влияние дискур- сивных структур и экстралингвистических факторов на формирование смысла [Cameron, 1997, p. 45]. Вместе с тем с точки зрения комплементарности оба подхода, по мнению Г. Маутнер, представляют собой естественное сочетание [Mautner, 2009, p. 33]. Применение методов дискурсивного анализа и корпусной лингвистики способствует изучению социальных смыслов языковых структур с опорой на их статистическую значимость и преодолению таким образом недостатков количественных методов, посредством которых считают то, что легко сосчитать [Stubbs, Gerbig, 1993], и качественных методов, посредством которых обнаруживают то, что ожидают найти [Stubbs, 1997].

Интеграция количественных и качественных методов характерна для ряда современных подходов к анализу дискурса. Их названия различаются терминологически по целям: корпусный критический анализ дискурса («corpusbased CDA», см., например: [Baker, 2006]); дискурс-анализ, проводимый с применением корпусных методов («corpus-assisted discourse studies», CADS, см., например: [Partington, 2004]); корпус и дискурс-анализ («corpora and discourse studies», см., например: [Baker, McEnery, 2015]). Исследования, выполненные в русле корпусной стилистики («corpus stylistics»), корпусной прагматики («corpus pragmatics») и корпусной социолингвистики («corpus-based sociolinguistics») [Friginal, Hardy, 2014], ставят перед собой цели, соотносимые с проблематикой дискурс-анализа.

В данной работе обобщены результаты корпусного исследования дискурсивной ценности разделительного вопроса как особого типа высказывания на материале корпуса британской устной речи. Сочетание количественных и качественных методов анализа языкового материала позволило рассмотреть этот объект в ракурсах функциональносинтаксического моделирования, корпусного представления с учетом значимых социокультурных маркеров дискурса, а также лингвопрагматической интерпретации и получить достоверные данные об особенностях реализации прототипических признаков и дискурсивных функциях разделительного вопроса в рамках британской традиции межличностного общения. 


\section{Материал и методы}

Английский разделительный вопрос как разновидность синтаксической модели речи часто становился объектом наблюдения, но если в первой половине XX в. его рассматривали как одну из нормативных синтаксических структур построения вопросительного предложения в английском языке [Algeo, 1988; Biber et al., 1999; Dubois, Crouch, 1975; Holmes, 1983; Quirk et al., 1985; и др.], то к началу XXI в. от системно-структурной характеристики англисты перешли к описанию его функциональной семантики и прагматики [Иванова, Бурлакова, Почепцов, 1981; Прибыток, 2008; Downing, 2015; Nässlin, 1984], появились работы о социолингвистическом и этносоциопрагматическом контексте использования разделительного вопроса [English Language..., 2018; Lakoff, 1975; Pearson, West, Turner, 2005; Tottie, Hoffmann, 2006; 2009]. Следует отметить, что при общем достаточно четком и логичном описании правил построения разделительного вопроса в английском языке исследователи указывают на вариативность его синтаксической организации, зависящей от мотивированности использования в речи в условиях межличностного общения [Евсикова, 2017; Коготкова, 2013; Кожедуб, 2017; Лебедева, 2019; Селезнева, Евсикова, Тарвердян, 2019]. В публикациях Д. Кимпс представлено детальное описание синтаксической структуры и коммуникативной значимости английского разделительного вопроса, основанное на данных корпусного анализа [Kimps, 2007; 2018]. Краткий обзор публикаций о разделительном вопросе в английском языке свидетельствует о неисчезающей актуальности его изучения в дискурсивно-прагматическом ракурсе.

Ранее мы обращались к проблеме социокультурной ценности разделительного вопроса в англоязычном межличностном общении [Ильинова, Кочетова, 2018]. С помощью корпусно-ориентированного прагмасоциолингвистического анализа было доказано, что разделительный вопрос является одной из форм дискурсивной саморепрезентации личности, отражающей такие конвенции англоязычного межличностного общения, как коммуникативное дистанцирование и интонирование вербальных действий с учетом социального и ролевого статуса личности. Социально-демографические, региональные, возрастные метаданные о синтаксических вариантах разделительного вопроса, извлеченные из Британского национального корпуса устной речи, подтвердили умеренную степень дискурсивной ценности исследуемой формы речи для англоязычной коммуникации, показали низкий уровень гендерной зависимости выбора варианта разделительного вопросительного предложения, статистические расхождения его использования представителями разных социальных и возрастных групп на синхронном срезе, методика диахронного сравнения позволила обнаружить снижение частотности использования данной формы речи представителями молодого поколения в современной Британии [Ильинова, Кочетова, 2018]. Выявленные факты потребовали продолжения исследования соотношения синтаксической вариативности модели разделительного вопроса и его функционально-прагматической ценности в англоязычной межличностной коммуникации. К данному моменту отсутствуют научные публикации, в которых было бы собрано достоверное число фактов, полученных с помощью инструментов корпусного анализа, верифицирующих коммуникативные функции английского разделительного вопроса в их соотношении с представленными в англоязычном межличностном общении моделями и вариантами реализации.

В основу данного исследования была положена следующая гипотеза: разделительное вопросительное высказывание (далее PBВ) является значимой для англоязычной коммуникативной культуры формой речи, которая используется для реализации интенций самопрезентации личности и поддержания межличностных отношений; его отличает полярно организованная синтаксическая структура, получающая в речи вариативную реализацию; сочетание приемов формально-синтаксического и глубинного дискурсивно-прагматического анализа с опорой на корпусноориентированный анализ форм, маркирующих PBВ, открывает возможности для реконструкции нормативных и ненормативных (узуальных) вариантов модели РВВ, выявления общего списка коммуникативно-прагматических интенций и определения их дискурсив- 
ной ценности в англоязычной коммуникативной культуре.

Объектом анализа стало английское разделительное вопросительное высказывание, предметом - формальные и функциональнопрагматические особенности его построения и использования в речи как конституента коммуникативного кодекса в англоязычном межличностном общении.

В статье решаются следующие задачи: на основе прототипических признаков английского РВВ, грамматически маркированных тэг-операторами, установить типы моделей PBB, уточнить прагматические и социокультурные особенности этой формы речевого поведения в англоязычной практике межличностного общения.

Материалом исследования послужили включающие разделительные вопросы диалогические единства, полученные в результате выборки из художественных произведений современных британских писателей ${ }^{1}$ (общий объем - 228 контекстов). Кроме того, материал для исследования был извлечен из корпуса британской устной речи BNC2014 2 объемом 11422617 слов. С помощью инструментов корпусного анализа отобрано 29119 контекстов употребления исследуемой синтаксической модели РВВ. Для анализа был установлен порог отсечения на уровне 3 случаев использования каждой структуры; конструкции, используемые менее 3 раз не рассматривались. Распределение структур в корпусе показывает, что они встречаются в 1229 текстах из 1 251, то есть разделительный вопрос используется практически во всех текстовых образцах. Относительная частота использования составляет $2549,241$.

Анализ контекстов реализации прототипической модели РВВ показывает, что ее варианты активно используются в межличностном общении для уточнения фактов, поддержания разговора, демонстрации согласия, несогласия, сомнения, выражения эмоционального отношения к партнеру или теме разговоpa. С точки зрения логического синтаксиса PBВ указывают на интенцию «запроса о реальности, выраженной в предикативной связи по отношению к утвердительной части предложения» [Иванова, Бурлакова, Почепцов, 1981, с. 180]. У носителей английского языка есть два нормативных варианта модели построения подобного предложения, они различаются по признаку синтаксической контрастности предикативных составляющих высказывания. Нормативная синтаксическая модель PBB в рамках работ по структурной лингвистике была описана как биполярная синтаксическая структура, включающая в первую очередь декларативную основу (констатирующая часть высказывания - statement, anchor) и интеррогативную часть (вопросительный тэг с нормативным синтаксическим оператором) [Algeo, 1988; Biber et al., 1999; Quirk et al., 1985]. Биполярность считается нормативным правилом построения английского разделительного вопроса, оно допускает два синтаксических варианта модели РВВ: если в констатирующей части стоит положительное утверждение, то в тэге требуется использовать в качестве оператора глагол-заместитель в отрицательной форме; если в констатирующей части сказуемое построено с использованием отрицания, то в тэге глагол-оператор должен стоять в не-отрицательной форме [Downing, 2015]. В соответствии с формально-грамматической нормой английского языка при объединении биполярных по знаку основы и тэга-переспроса говорящий должен выбрать для тэга грамматически адекватную форму оператора (be, do, have) с учетом времени, аспекта и лица знаменательного глагола в функции основного сказуемого. В ходе данного исследования был применен корпусный анализ для статистической проверки особенностей реализации синтаксической модели РВВ в коммуникативной практике, в качестве маркеров РВВ использовались тэгоператоры английского языка.

Корпус британской устной речи отразил объективную картину использования разделительного вопроса в речи носителей британского варианта английского языка, для которой, наряду с нормативными примерами реализации модели РВВ, характерны ненормативные варианты. В частности, наблюдаются отклонения от нормы синтаксической бинарности PBВ, выраженные в использовании в качестве тэга не только традиционных форм вспомогательных глаголов и грамматически соответствующих им местоименных замен. В разговорной речи отмечаются тэги, морфо- 
логически независимые от формы глагола в главном предложении weren't it?, don't she?, don't he?, don't it?, weren't she?, например: oh it was Bob weren't it? [Tottie, Hoffmann, 2006, p. 286]; S0689: I think Donna's a bit older than him weren't she?; S0012: he keep wanting to come in the window do n't he?; S0421: oh I like those bushes; S0423: >> it looks quite nice do n't it? (.) yeah. В устной разговорной речи наблюдается искажение произнесения тэга в утвердительной части с именным сказуемым to be, что отражено в корпусе примеров с помощью особой графической фиксации усеченной формы тэга-переспроса innit?, например: It's boring life really, innit really? [Tottie, Hoffmann, 2006, p. 286]. Все указанные особенности автоматизированного поиска РВВ в корпусе по знаку тэга были учтены в данном исследовании.

\section{Результаты и обсуждение}

\section{Структурно-синтаксическое моделирование разделительного вопросительного высказывания}

Обращение к процедуре структурно-синтаксического анализа реализации РВВ в корпусах британской устной речи и современной британской прозы позволило собрать данные об отклонениях от прототипической биполярной модели РВВ в образцах живой речи. Не отрицая ее значимости, мы отметили варианты PBВ с ненормативной синтаксической полярностью сочетания основы и тэга, в частности случаи, когда в обеих частях разделительного вопроса в позициях основного сказуемого и тэга используются отрицательные или не-отрицательные формы глаголов. По данным корпусного анализа, ненормативные монополярные модели могут быть отмечены в британском корпусе устной речи позитивными знаками предикативной формы в обоих частях РВВ, например: S0198: oh it's got a little two gigabyte User mini card in it has it?; S0653: er it cost a thousand pounds for the holiday did it?, а также могут иметь предикативную часть с отрицанием, например: You don't know what that is, though, don't you? (RR, p. 37) - или предикативную часть, содержащую лексическую единицу с отрица- тельной оценочной семантикой, например: S0519: the last two summers have been hugely disappointing haven't they?

Выявляемые отклонения от нормы биполярности в речи англичан считаются приемлемыми, функционально зависящими от контекста ситуации [Algeo, 1988; Downing, 2015; Fox, 2004; Kimps, 2018]. Для обозначения монополярных моделей в этой работе предлагается рабочий термин «узуальная монополярность». Признак узуальности указывает на частную норму обиходного общения [Сиротинина, 2013]. Будучи тесно связанными с синтаксическим прототипом РВВ, узуальные модели разделительного вопроса отражают вариативность речевого поведения и имеют прагматическое обоснование в границах коммуникативной ситуации. Собранные зарубежными коллегами корпусы устной и письменной речи [English Language..., 2018; Nässlin, 1984; Tottie, Hoffmann, 2006; и др.] и статистические данные нашего корпусноориентированного анализа указывают на наличие четырех моделей построения $\mathrm{PBB}$ с нормативной и ненормативной полярностью (см. табл. 1).

Узуальность проявляется не только в допустимости моделей би- и монополярности двух конституентов высказывания, но и, как показывает корпусный анализ (см., например: [Nässlin, 1984; Algeo, 1988; Tottie, Hoffmann, 2006; Ильинова, Кочетова, 2018]), в наличии в устной речи синтаксически усеченных реализаций РВВ (например, Makes you really think, doesn't it?; You are joking, eh?; She is a nice lady, don't you think?), РВВ с морфологически независимым тэгом (She is a lovely girl, is $\boldsymbol{A n n}$ ?) или несистемным тэгом ( $W E$ 've finished, and so have you) [Downing, 2015]. Узуально в англоязычном межличностном общении в качестве предикативной базы разделительного вопроса могут воспроизводиться как повествовательные, так и восклицательные и императивные структуры, завершающиеся тэгами, например: How nice you did it, didn't you? (восклицание), Stop interrupting me all the time, would you? (императив). Отметим еще одно отклонение от прототипа PBB. Грамматические правила английского языка предписывают финальную локацию тэга-переспроса (You've lost the money, have 
Таблица 1. Модели нормативной и узуальной полярности разделительного вопросительного высказывания в английском языке

Table 1. Tag questions in the English language with standard and common usage polarity types

\begin{tabular}{|c|c|c|c|c|c|c|c|}
\hline \multicolumn{4}{|c|}{ Standard polarity } & \multicolumn{4}{|c|}{ Common usage polarity } \\
\hline \multicolumn{2}{|c|}{$\begin{array}{l}\text { Model } 1 \\
\text { Positive anchor / Negative } \\
\operatorname{tag}(+/-)\end{array}$} & \multicolumn{2}{|c|}{$\begin{array}{l}\text { Model } 2 \\
\text { Negative anchor / Positive } \\
\operatorname{tag}(-/+)\end{array}$} & \multicolumn{2}{|c|}{$\begin{array}{l}\text { Model 3 } \\
\text { Positive anchor / Positive } \\
\operatorname{tag}(+/+)\end{array}$} & \multicolumn{2}{|c|}{$\begin{array}{l}\text { Model } 4 \\
\text { Negative anchor / Negative } \\
\operatorname{tag}(-/-)\end{array}$} \\
\hline $\begin{array}{l}\text { This matter } \\
\text { makes you } \\
\text { think } \\
\text { negatively, }\end{array}$ & doesn't it? & $\begin{array}{l}\text { This matter } \\
\text { didn't make } \\
\text { you change } \\
\text { your } \\
\text { opinion, }\end{array}$ & did it? & $\begin{array}{l}\text { This matter } \\
\text { makes you } \\
\text { think } \\
\text { negatively, }\end{array}$ & does it? & $\begin{array}{l}\text { This matter } \\
\text { didn't make } \\
\text { you change } \\
\text { your } \\
\text { opinion, }\end{array}$ & didn't it? \\
\hline
\end{tabular}

Примечание. Знаком «+» обозначено использование глагола в утвердительной форме, знаком «-» обозначено использование отрицательной формы глагола.

Note. "+" marks the positive form of the verb; "-" marks the negative form of the verb.

$\boldsymbol{y o u} ?)$, но в материале исследования были выявлены иные локации, например в середине главного предложения, справа от основной предикативной части: It's easy, isn't it, to get used to this new style?, что отражает прагматические интенции говорящего в момент порождения высказывания.

При реализации РВВ в англоязычном межличностном общении узуальность проявляется в использовании в тэге модальных слов и фраз вместо одной из форм вспомогательных глаголов $b e, d o$, have в позиции оператора. Причины обращения к модальным словам кроются в конвенциях межличностного общения в англоговорящем социуме [Ларина, 2003; Лебедева, 2019; Fox, 2004]. Представляется, что англичане избирают в качестве тэга модальные глаголы (will / can / might / have to), способные дополнить основное содержание предикативной части высказывания коммуникативной тональностью уверенности, сомнения, вероятности свершения события, например: You will never come back there, won't you? You will come back one day, will you? Объяснение выбора формы и коммуникативных функций модальных тэгов будет представлено в следующем разделе статьи.

Выделив дискурсивные реализации четырех моделей, составляющих нормативноузуальный базис РВВ в английском языке, мы извлекли число их реализаций в корпусе устной британской речи и проанализировали дистрибуцию употребления разделительного вопроса с различными тэгами.
Общее число извлеченных из корпуса примеров для грамматического и конституентного анализа РВВ составило 29119 единиц, из них: $31,62 \%$ - вопросительные разделительные предложения с тэгами, включающими в качестве оператора отрицательные формы глагола $b e$ в настоящем времени, 6,85\%- включающими в качестве операторов отрицательные формы глагола $b e$ в прошедшем времени; $20,97 \%$ - вопросительные разделительные предложения с тэгами, включающими в качестве оператора положительные формы глагола $b e$ в настоящем времени, 6,08 \% - включающими в качестве оператора положительные формы глагола $b e$ в прошедшем времени; 8,67 \% - вопросительные разделительные предложения с тэгами, включающими в качестве оператора отрицательные формы глагола $d o$ в настоящем времени, 5,02 \% - включающими в качестве оператора отрицательные формы глагола $d o$ в прошедшем времени; 5,38 \% - вопросительные разделительные предложения с тэгами, включающими в качестве оператора положительные формы глагола $d o$ в настоящем времени, 4,09 \% - включающими в качестве оператора положительные формы глагола $d o$ в прошедшем времени; 2,75 \% - вопросительные разделительные предложения с тэгами, включающими в качестве оператора отрицательную форму глагола have в настоящем времени, $1,55 \%$ - включающими в качестве оператора положительные формы глагола have. Из модальных глаголов в корпусе представлен глагол will в положительной и отрицательной форме $-0,58$ и $1,48 \%$ соответственно. 
Разделительные вопросы, образованные с использованием в тэге-операторе модальных глаголов will, must, can, need, might, которые дополняют основное содержание предикативной части высказывания коммуникативной тональностью уверенности, сомнения, вероятности свершения события (например: S0012: yeah they might have to be moving to Florida shortly, mightn't they?; You will never come back there, won't you? You will come back one day, will you? I must't listen to your hotty recommendations, musn't I?), также вошли в общие количественные данные, хотя их использование отличается низкой частотностью. В таблице 2 представлены сводные данные, указывающие на выявленные предпочтения в использовании нормативных бипо- лярных и узуальных монополярных моделей PBB с учетом базовых синтаксических вариантов оператора тэга-переспроса (be, do, have, will, can, might), полной или усеченной синтаксической реализации основной части $\mathrm{PBB}, \mathrm{a}$ также низкочастотные случаи ненормативного смешения глагольных форм в основной части и в тэге-переспросе при сохранении узуальных норм РВВ.

Из данных таблицы 2 следует, что в общей коллекции примеров доминируют модели c оператором be в позиции тэга-переспроса (17 828 единиц, 61,6 \% от общего числа разделительных вопросов), модели с оператором do составляют 6854 случая $(25,45 \%)$, с оператором have - 1334 случая $(4,66 \%)$, с оператором, в качестве которого выступают мо-

Таблица 2. Разделительный вопрос с операторами be, do, have, will, can, might в корпусе BNC2014

Table 2. Tag questions with the verb operators be, do, have, will, can, might in BNC2014

\begin{tabular}{|c|c|c|}
\hline \multirow{2}{*}{ Форма оператора } & \multicolumn{2}{|c|}{ Количество употреблений } \\
\hline & Абсолютное выражение & $\%$ \\
\hline \multicolumn{3}{|c|}{ 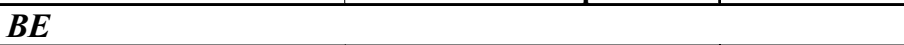 } \\
\hline isn't it? & 7175 & 24,64 \\
\hline is it? & 4392 & 15,08 \\
\hline was it? & 1290 & 4,43 \\
\hline aren't they? & 1249 & 4,29 \\
\hline wasn't it? & 1204 & 4,13 \\
\hline are they? & 833 & 2,86 \\
\hline is he? & 537 & 2,23 \\
\hline isn't he? & 517 & 1,78 \\
\hline is she? & 406 & 1,39 \\
\hline weren't it? & 225 & 0,77 \\
\hline Bcezo & 17828 & 61,6 \\
\hline \multicolumn{3}{|l|}{ DO } \\
\hline don't they? & 1215 & 4,17 \\
\hline doesn't it? & 950 & 3,26 \\
\hline Do they? & 648 & 2,23 \\
\hline Didn't they? & 490 & 1,68 \\
\hline Does it? & 487 & 1,68 \\
\hline Didn't he? & 435 & 1,49 \\
\hline Did he? & 393 & 1,35 \\
\hline Did they & 359 & 1,23 \\
\hline Didn't it? & 266 & 1,11 \\
\hline Does he? & 253 & 0,81 \\
\hline Didn't she? & 244 & 0,84 \\
\hline Did she? & 236 & 0,84 \\
\hline Doesn't he? & 235 & 0,84 \\
\hline Did it? & 204 & 0,70 \\
\hline Does she? & 178 & 0,61 \\
\hline Doesn't she? & 151 & 0,52 \\
\hline Don't it? & 110 & 0,38 \\
\hline Bсеzo & 6854 & 25,45 \\
\hline
\end{tabular}


Окончание таблищы 2

End of Table 2

\begin{tabular}{|c|c|c|}
\hline \multirow{2}{*}{ Форма оператора } & \multicolumn{2}{|c|}{ Количество употребллений } \\
\hline & Абсолютное выражение & $\%$ \\
\hline \multicolumn{3}{|l|}{$\overline{H A V E}$} \\
\hline Haven't they? & 325 & 1,23 \\
\hline Hasn't it? & 211 & 0,72 \\
\hline Have they? & 202 & 0,70 \\
\hline Has he? & 181 & 0,62 \\
\hline Hasn't he? & 165 & 0,57 \\
\hline Has it? & 130 & 0,41 \\
\hline Has she? & 120 & 0,41 \\
\hline Bcezo & 1334 & 4,66 \\
\hline \multicolumn{3}{|l|}{ WILL } \\
\hline Won't it? & 216 & 0,74 \\
\hline Won't they? & 133 & 0,46 \\
\hline Will it? & 65 & 0,22 \\
\hline Won't he? & 45 & 0,15 \\
\hline Will they? & 44 & 0,15 \\
\hline Won't she? & 44 & 0,15 \\
\hline Will he? & 35 & 0,12 \\
\hline Will she? & 30 & 0,10 \\
\hline Bcezo & 612 & 2,09 \\
\hline \multicolumn{3}{|l|}{ CAN } \\
\hline Can't they? & 59 & 0,20 \\
\hline Can they? & 45 & 0,15 \\
\hline Can it? & 45 & 0,15 \\
\hline Can't it? & 31 & 0,11 \\
\hline Can he? & 25 & 0,09 \\
\hline Can't he? & 24 & 0,08 \\
\hline Can she? & 20 & 0,07 \\
\hline Can't she? & 7 & 0,02 \\
\hline Всего & 256 & 0,87 \\
\hline \multicolumn{3}{|l|}{ "MIGHT } \\
\hline Mightn't it? & 10 & 0,03 \\
\hline Mightn't they? & 7 & 0,02 \\
\hline Might they? & 3 & 0,01 \\
\hline Might it? & 3 & 0,01 \\
\hline Bсеzo & 23 & 0,07 \\
\hline $\begin{array}{l}\text { Paзноe: } \\
\text { Do he? Had they? Had } \\
\text { she? Weren't she? }\end{array}$ & 2212 & 5,78 \\
\hline
\end{tabular}

дальные глаголы will, might, can, - 891 случай, что составляет $3,03 \%$. Как показывает анализ корпуса, разделительные вопросы имеют тенденцию к использованию с местоимениями третьего лица единственного и множественного числа, при этом наиболее частотным является местоимение it. Конструкции с глаголом be в 6347 случаях $(35,6 \%$ от 17828 контекстов употребления) - это реализации нормативной биполярной Модели 1 (позитивное утверждение и тэг-переспрос с отрицательной формой вспомогательного глаго- ла $b e$ в качестве оператора; в конструкции с глаголом $d o$ нормативный вариант Модели 1 встречается в 14,06 \% - 4039 контекстов употребления). Представляется, что при использовании нормативной модели говорящий стремится выразить собственное видение ситуации и получить подтверждение его правильности, например: I'm looking for Elizabeth. Yes, you're a friend of hers, aren't you? Don't worry, you never remember me (EH-44); You know who he is, don't you? He's Morris Stemmer, you'll have heard of him (RR-141). 
Сходная интенция выявляется и при активном использовании нормативной биполярной Модели 2 с тэгами do, did, does, are (64 случая $33,3 \%$ от 192), когда требуется подтверждение обратного, например: S0192: they 're not gon na fine us or anything though, are they? I've tried to contact them. Модель 3 с узуальной монополярностью и операторами $B E$ и $D O$ - это ненормативный вариант, такие случаи представлены в тэгах does he?, did she?, does he?, did he? в полной синтаксической реализации: S0198: yeah, definitely works, does it?; not everyone who goes to Oxford and Cambridge are posh, are they? Just most of them I suppose.

Данные нашего корпусного анализа свидетельствуют о высокой востребованности нормативной биполярной Модели 1 , частом обращении к биполярной Модели 2, а также узуальной однополярной Модели 3 (с двумя позитивными глагольными формами в позициях утверждения и тэга-переспроса). В таблице 3 представлены данные о сравнении реализаций Модели 2 и Модели 3.
Как показывает статистика корпусного анализа, случаи смешения синтаксических операторов составляют $1,23 \%$ от общего числа единиц, но их выбор в речевой практике имеет прагматическую ценность - это интонационно маркированная адресованность высказывания, например: S0230: but everything seems so big when you're ten years old, don't it?; well I don't, that don 'ts- seem right, do it?; Your food smells of that, don't it?; that was a long journey, weren't it?

Количественный подсчет реализаций моделей PBВ с модальными операторами указывает на их относительно низкую востребованность (891 случай, или 3,03 \%), при этом 1,92 \% (559 случаев) - это реализация нормативной биполярной Модели 1; Модели 2 и 3 представлены в $22,2 \%$ (70 случаев) и $19,4 \%$ (17 случаев) соответственно, в качестве модальных операторов доминирует форма will, которая может использоваться в конструкциях, требующих оформления при помощи других вспомогательных глаголов, например: S0104: They're not going to hear that will they?; S0278: they don't want

Таблица 3. Распределение разделительных вопросов в соответствии с нормативной биполярной моделью $(-/+)$ и ненормативной однополярной моделью (+ / +) в BNC2014

Table 3. Breakdown of canonical tag questions with polarity types $(-/+)$ and $(+/+)$ in BNC2014

\begin{tabular}{|c|c|c|c|c|}
\hline \multirow{2}{*}{$\begin{array}{l}\text { Форма } \\
\text { оператора }\end{array}$} & \multicolumn{2}{|c|}{ Модель 2 (нормативная $(-/+))$} & \multicolumn{2}{|c|}{ Модель 3 (ненормативная $(+/+))$} \\
\hline & $\begin{array}{c}\text { Частота } \\
\text { употребления }\end{array}$ & $\begin{array}{c}\text { \% от общего числа } \\
\text { употреблений }\end{array}$ & $\begin{array}{c}\text { Частота } \\
\text { употребления }\end{array}$ & $\begin{array}{c}\text { \% от общего числа } \\
\text { употреблений }\end{array}$ \\
\hline \multicolumn{5}{|c|}{ J } \\
\hline is it? & 3039 & 69,2 & 1353 & 30,8 \\
\hline was it? & 310 & 24,0 & 980 & 76,0 \\
\hline are they? & 508 & 61,0 & 325 & 39,0 \\
\hline is he? & 350 & 65,2 & 187 & 34,8 \\
\hline is she? & 253 & 62,2 & 153 & 37,7 \\
\hline \multicolumn{5}{|l|}{$\mathrm{DO}$} \\
\hline Do they? & 525 & 80,96 & 123 & 19,04 \\
\hline Does it? & 447 & 91,9 & 40 & 8,1 \\
\hline Did he? & 268 & 68,2 & 125 & 31,7 \\
\hline Did they & 284 & 79,2 & 75 & 20,7 \\
\hline Does he? & 164 & 64,7 & 89 & 35,3 \\
\hline Did she? & 150 & 63,4 & 86 & 34,6 \\
\hline Does he? & 163 & 64,4 & 90 & 35,6 \\
\hline Did it? & 175 & 85,7 & 29 & 14,3 \\
\hline Does she? & 151 & 88,5 & 20 & 11,5 \\
\hline \multicolumn{5}{|l|}{ HAVE } \\
\hline Have they? & 136 & 67,5 & 66 & 32,5 \\
\hline Has he? & 124 & 68,8 & 57 & 31,2 \\
\hline Has it? & 71 & 54,9 & 59 & 45,1 \\
\hline Has she? & 85 & 70,2 & 35 & 29,8 \\
\hline
\end{tabular}


to be there will they? Следует отметить, что любое глагольное сказуемое с модальным дополнением нельзя назвать утверждением, поскольку модальные глаголы и модальные фразы добавляют к общему содержанию утверждения экспликацию субъективного мнения, субъективной оценки ситуации или отношений между людьми. Именно это обстоятельство делает РВВ с модальным компонентом в главном сказуемом и вопросительном тэге удобным инструментом установления коммуникативной дистанции и стилистического интонирования речи. Подтверждением тому могут стать примеры использования Модели 2 (биполярная с отрицанием в утвердительной части) и Модели 3 (монополярная с двумя утверждениями): S0591: not sure that jade can be plural can it?; Robin! It can be a girl's name, can it?; His father will pay it but I think it would be more polite and - well, kinder, to send it to Joel, don't you? (RR-219). Смешение глагольных форм в функции операторов демонстрирует интенцию кооперативности, призывает к совместному принятию решения.

Завершая раздел о структурно-синтаксическом моделировании реализаций РВВ в британском варианте устной коммуникации, отметим, что представленные данные подтверждают гипотезу о существовании нормативноузуальных моделей построения РВВ в синтаксисе английского языка, о некоторых различиях в их востребованности в речи, однако они не дают ответа на вопрос о причинах разнообразия вариантов обращения к ним, о выборе модальных операторов вместо традиционных вспомогательных глаголов, о возможных интенциях смешения тэгов переспроса. После обобщения количественных данных обратимся к изучению прагматической значимости нормативных и узуальных моделей РВВ в англоязычном межличностном общении.

\section{Лингвопрагматическая ценность разделительного вопросительного высказывания в англоязычной культуре общения}

Вторая часть исследования посвящена изучению лингвопрагматики PBВ как формы коммуникативного действия, обладающего ценностью для соблюдения коммуникативного кодекса в англоязычном общении. На ос- нове метода лингвопрагматической интерпретации коллекции примеров были выделены коммуникативно-прагматические интенции PBВ и предложены их ценностно ориентированные толкования.

Первые размышления о прагматике разделительного вопроса появились в работах английских и американских социолингвистов и специалистов по речевому этикету [Algeо, 1988; Brown, 1987; Dubois, Crouch, 1975; Fox, 2004; Holmes, 1983; Lakoff, 1975; Pearson, West, Turner, 2005; Quirk et al., 1985; и др.]. В публикациях были представлены некоторые наблюдения над прагматическими характеристиками разделительного вопроса, высказаны предположения о его значимости для коммуникативного взаимодействия в связи с фактами включенности синтаксических моделей разделительного вопроса в сложные синтаксические единства высказываний, в частности, когда они вводятся в общение инициальными фразами I think, I consider, I reckon, I suppose, призванными внести в общение отстраненность говорящего от высказываемого им утверждения: I think, he left before lunch, didn't he? В отечественной англистике мысли о прагматических характеристиках были сформулированы Г.Г. Почепцовым: разделительный вопрос в силу смысловой контрастности частей придает высказыванию выразительность и смысловую определенность [Иванова, Бурлакова, Почепцов, 1981, с. 180]. В некоторых публикациях зарубежных ученых представлены авторские гипотезы о социокультурном и прагматическом фоне (контексте) его употребления в речи (см., например: [Lakoff, 1975; Pearson, West, Turner, 2005]).

Наблюдения над прагматикой разделительного вопроса нашли отражение в статьях Р. Лакофф. В них она указала на тональность прагматической неопределенности, которую придает разговору разделительный вопрос: «So a tag-question is really intermediate between a statement and a question: a statement assumes that the addressee will agree, and a question leaves the response of the addressee up to him, but a tag-question implies that, while the speaker expects a certain sort of response, the hearer may not provide it» [Lakoff, 1975, p. 21] - Таким образом, в разделительном вопросе объединяются признаки утверждения и вопроса: ут- 
вердительная часть вопроса предполагает согласие адресата с содержанием информации, вторая часть (тэг-переспрос) маркирует ожидание говорящего на поддержку своего мнения, но допускает и возможность отказа (перевод наш. - Л. К., Е. И.). Как следует из приведенного комментария, тэг-переспрос выполняет коммуникативно-дискурсивную функцию - позволяет говорящему передать слушающему сигнал о своем личном мнении, намекнуть на ожидание подтверждения, но при этом за слушающим остается право принять чужое личное мнение, отклонить его, выразить собственное.

В академической грамматике английского языка А. Даунинг разбор конструктивных особенностей разделительного вопроса сопровождается некоторыми прагмадискурсивными комментариями. В частности, если структурно синтаксическая основа вопроса точно следует грамматическому предписанию о полярности предикативной составляющей констатирующей части первого предложения и морфограмматической форме вопросительного тэга (при свободной вариативности их использования в высказывании), то в содержательном плане разделительный вопрос используется не столько для информирования или запроса информации, сколько для передачи личностных интенций человека в ходе общения [Downing, 2015]. Иными словами, автор указывает на наличие речевой (коммуникативной) тональности, допускающей вариативность модальности высказывания: в устной речи вопросительные тэги могут произноситься с восходящей интонацией, передавая интенцию неуверенности, сомнения, призывая к подтверждению сказанного (Am I right?), а нисходящая интонация позволяет передать уверенность в правильности высказанного и ожидание непременного подтверждения, согласия со стороны партнера (I'm asking you to confirm this; I am seeking for agreement) [Downing, 2015, p. 123-124]. По мнению А. Даунинг, в англоязычной речи также можно обнаружить разделительный вопрос с «нулевой полярностью», передающий уверенность правильного понимания сказанного, что представлено в сочетании повествовательных предложений (утверждений) с позитивным знаком в вопросительной части.
Такие высказывания сопровождаются дискурсивными словами-междометиями $\mathrm{Oh}$, So, Well, Now. Возможно, они указывают на дополнительную прагматическую интенцию говорящего - придать своему высказыванию вид фразы, завершающей обсуждение, взять на себя право подводить итоги беседы, делать выводы (So, that's what they call them now, don't they?). Однако те же слова могут передавать и знаки эмоциональной импликатуры, например выражать удивление: $O h$, so уоu are our new assistant, are you? - или негативное отношение: Well, I reckon so that's what she said about me, is it?

В речевой практике все исследователи наблюдают варианты с полным рассогласованием правила биполярности частей разделительного вопроса (об этом мы сообщали ранее). Узуально допустимые реализации моделей РВВ объясняются интенцией говорящего проявить себя, выразив личную субъективную оценку, установить коммуникативную дистанцию, продемонстрировать эмпатию, они позволяют создавать и поддерживать межличностные контакты в ходе общения. Это может быть такая прагматическая интенция, как демонстрация вежливого интереса к высказыванию малознакомого / незнакомого человека. Например, в следующей ситуации, когда на реплику шофера такси I think I've lost my way возможна реакция вежливого удивления пассажира Have you? / You do?/ You have? [Downing, 2015, p. 124]).

Приведенные сведения о прагматической значимости разделительного вопроса обусловили необходимость обратиться к детальному анализу причин разной частотности использования в речевой практике англичан описанных выше формально-синтаксических моделей РВВ и их нормативных и узуальных вариантов, с помощью которых маркируется прагматическая нагруженность высказывания в границах коммуникативной ситуации.

В результате анализа коллекции собственного аутентичного материала (228 ситуаций с РВВ в качестве центрального компонента) был сделан вывод о поликоммуникативной функциональности, которая формально обеспечивается относительно малым числом языковых маркеров и конструкций, позволяющих передавать требуемые коммуника- 
тивные интенции и стилистические тональности общения. Следуя коммуникативному кодексу неимпозитивного и вежливого общения [Ларина, 2003; 2013; Brown, Levinson, 1987], англичане могут заменять нормативные морфологические операторы PBB (auxiliary verb tags be, do, have) на модальные (will, would, shall, need, can), что способствует реализации стратегий позитивной или негативной вежливости, усилению или смягчению прагматики высказывания.

При проведении дискурсивно-прагматического анализа была принята следующая методика: 1) сбор диалогических фрагментов с центральным компонентом «разделительное вопросительное высказывание»; 2) определение социопрагматического фона интеракций с разделительным вопросительным высказыванием (воссоздание «портрета говорящего» и «портрета слушающего»- определение возрастных, гендерных, иных социально значимых данных, установление характера межличностных отношений в интеракции); 3) конструктивный анализ разделительного вопроса и отнесение его к одной из четырех моделей $\mathrm{PBB}$, выделение грамматического оператора в качестве маркера разновидности модели; 4) установление прагматической силы (интенции) конкретного РВВ с учетом коммуникативной тональности его тэга и причисление его к одной из прагматических интенций: информационной, этикетной, корректирующей (фокуснопозитивной или фокусно-негативной).

Дадим краткую характеристику каждой разновидности интенции и разберем прагматические смыслы на примерах из нашей коллекции.

Информационная интенция разделительного вопроса понимается как стремление говорящего не столько сообщить информацию, сколько подтвердить ее правильность; он ждет от слушающего не конкретного ответа, а подтверждения, например: I mean, she's hardly going to identify herself, is she? (EH-205); You're not a friend of Mum's, are you? Did you want something? (ЕН-97); с помощью РВВ может быть выражено предложение поступка: You're going to give him the boot, though, aren't you? (RR-157). За такими высказываниями скрывается прагматика самодистанцирования и уважения к выбору возможного от- вета слушающим - запрашивая подтверждение по поводу информации, говорящий оставляет возможность для слушающего выбрать форму ответа, возразить.

Этикетная интенция межличностного общения представляет требование демонстрации взаимного уважения, соблюдения социальной (приватной) дистанции [Ларина, 2003]. Поэтому, если у человека, находящего в общественном месте, возникает необходимость вступить в общение, он может избрать разделительный вопрос в качестве зачина для разговора с незнакомым или малознакомым человеком. Так, если англичане оказываются вместе в замкнутом пространстве, то принято что-то сказать, чтобы продемонстрировать дружелюбие и вежливость, в такой ситуации может прозвучать этикетный разделительный вопрос о погоде, иных не табуированных для общения в публичном пространстве темах, например: It is chilly today, isn't it? Задавая вопросы Excuse me, this is the pass to Tothaynem Road, isn't it?; Excuse me, this bus will take me to Oxford Street, won't it?, говорящий выражает уверенность, что он идет в нужном направлении и просит подтверждения.

Корректирующая интенция представляется самой ценностной для понимания конвенций межличностного общения в англоговорящем сообществе. С помощью специального построения РВВ говорящий производит коррекцию социальной дистанции и выражает коммуникативную тональность. В результате анализа ситуаций мы пришли к выводу о двух направлениях коррекции межличностных отношений: фокусно-позитивной и фокуснонегативной стратегии коррекиии сочиальной дистаниии.

Фокусно-позитивная стратегия коррекиии проявляется в желании вовлечь второе лицо в разговор, найти подтверждение собственному высказыванию, при этом говорящий должен помнить о соблюдении коммуникативной дистанции, то есть придерживаться речевого этикета и позиционировать себя как человека, знающего и соблюдающего нормы неимпозитивности и сдержанности, принятой в англоязычной коммуникативной традиции. При разборе примеров в этом классе интенций мы отметили присутствие двух разновидностей - интенция запроса о сотрудни- 
честве, согласии (S0192: >> yoah we could make some wedges that might be quite tasty mightn't it) и выражение сомнения, неуверенности в себе, своем мнении (S0012: I don't think he drinks too much does he?).

Обе разновидности ориентированы на трансляцию позитивной вежливости, реализацию стратегий дистанцирования и взаимного позиционирования вежливости и неимпозитивности. Именно первая разновидность стратегии фокусно-позитивной коррекции отношений доминирует в нашем материале. Для передачи указанных интенций используются РВВ с разными моделями полярности, вопросительный тэг призван смягчить необходимость прямого обращения к партнеру, настойчивое желание узнать его мнение, например: S0192: >> but it's a bit more stable lately ... it hasn't been too bad (.) oh for that's no good is it? - S0195: yeah.

Фокусно-негативная стратегия коррекиии социальной дистанции проявляется при потребности указать на ролевое неравенство, выразить недовольство состоянием дел: How long d'you reckon he'll be? - Don't know, do I? I don't know where he's at, coming back like that, spying on me (RR-198); намекнуть на нарушения конвенций поведения: You are not trying to poison our relations, are you? (EH-136); Can't you see I'm working? You don't know what that is, though, do you? (RR-36); угрожать: Then I'll have to stop you, won't I? (RR-346); критикуя, оскорблять собеседника: You don't know a fucking thing about it, do you? (RR-72); приписывать ему роль невежды: Suppose she's just an honest woman? Didn't think of that, did you? No, you wouldn't (RR-37); выражать свое раздражение поведением другого человека, грубо отдалять его от себя: Stop interrupting me all the time, would you? (RR-112). В последней ситуации говорящий дает команду и усиливает позицию власти, добавляя тэг would you?. Представляется, что в зависимости от отношений этот тэг может передавать как интенцию раздражения и гнева, так и смягчения.

По завершении лингвопрагматического анализа была составлена сводная таблица 4 , показывающая статистику распределения примеров РВВ в соответствии с реализованными интенциям.

Детальный анализ количественных и качественных признаков реализации моделей РВВ и сопоставление частотности их использования для выражения выделенных интен-

Таблица 4. Сводные данные о реализации дискурсивно-прагматических интенций в англоязычных разделительных вопросительных высказываниях с учетом их синтаксической представленности в нормативно-узуальных би- и монополярных моделях

Table 4. Breakdown of tag questions with bi- and mono-polarity model types in relation to their discourse-and-pragmatic intentions in speech discourse

\begin{tabular}{|c|c|c|c|c|c|c|c|}
\hline \multirow{4}{*}{ Модели } & & \multicolumn{5}{|c|}{ Разновидности интенций } & \multirow{4}{*}{ Всего } \\
\hline & & \multirow{3}{*}{$\begin{array}{l}\text { Информа- } \\
\text { ционная }\end{array}$} & \multirow[t]{3}{*}{ Этикетная } & \multicolumn{3}{|c|}{ Корректирующая } & \\
\hline & & & & \multicolumn{2}{|c|}{ Фокусно-позитивная } & \multirow{2}{*}{$\begin{array}{c}\text { Фокусно- } \\
\text { негативная }\end{array}$} & \\
\hline & & & & $\begin{array}{c}\text { Запрос сотруд- } \\
\text { ничества помо- } \\
\text { щи, участия }\end{array}$ & $\begin{array}{c}\text { Выражение со- } \\
\text { мнения, неуве- } \\
\text { ренности }\end{array}$ & & \\
\hline \multirow{2}{*}{$\begin{array}{l}\text { Модель 1-2-3-4 } \\
\text { с операторами вспо- } \\
\text { могательными гла- } \\
\text { голами be, do, have }\end{array}$} & $\begin{array}{c}\text { Кол-во } \\
\text { ситуаций }\end{array}$ & 50 & 8 & 84 & 25 & 25 & 192 \\
\hline & $\%$ & 26 & 4 & 44 & 13 & 13 & 100 \\
\hline \multirow[t]{3}{*}{$\begin{array}{l}\text { Модель 1-2-3-4 } \\
\text { с модальными опе- } \\
\text { раторами }\end{array}$} & $\begin{array}{l}\text { Модаль- } \\
\text { ный опе- } \\
\text { ратор }\end{array}$ & (will / can) & $\begin{array}{c}\text { (won't / } \\
\text { wouldn't) }\end{array}$ & $\begin{array}{l}\text { (wouldn't / } \\
\text { won't/ } \\
\text { shouldn't/ } \\
\text { mightn't) }\end{array}$ & (would) & $\begin{array}{l}\text { (would / } \\
\text { wouldn't) }\end{array}$ & - \\
\hline & $\begin{array}{c}\text { Кол-во } \\
\text { ситуаций } \\
\end{array}$ & 3 & 13 & 11 & 3 & 6 & 36 \\
\hline & $\%$ & 8,1 & 36,8 & 30,8 & 8,1 & 16,2 & 100 \\
\hline \multirow[t]{4}{*}{ Итого } & Общее & 53 & 21 & \multicolumn{3}{|c|}{154} & \multirow[t]{2}{*}{228} \\
\hline & $\begin{array}{c}\text { кол-во } \\
\text { ситуаций }\end{array}$ & & & 95 & 28 & 31 & \\
\hline & \multirow[t]{2}{*}{$\%$} & \multirow[t]{2}{*}{23} & \multirow[t]{2}{*}{9} & \multicolumn{3}{|c|}{68} & \multirow[t]{2}{*}{100} \\
\hline & & & & 42 & 12 & 14 & \\
\hline
\end{tabular}


ций свидетельствует о доминировании в межличностном общении корректирующей интенции (154 ситуации - $68 \%$ от общего числа $228)$, в первую очередь такой ее разновидности, как фокусно-позитивная (запрос о сотрудничестве, помощи, участии, что составляет в целом 95 ситуаций - $42 \%$ от 228 ; выражение сомнения, неуверенности, 28 ситуаций, $12 \%$ ), фокусно-негативное регулирование также присутствует (31 ситуация - $14 \%$ от 228). Далее по количеству ситуаций располагаются примеры с информационной (53 ситуации, или $23 \%$ и и этикетной (21 ситуация, или $9 \%$ интенциями. Следует отметить, что прагматику этикетности и фокусно-позитивной коррекции отношений чаще передают модальные операторы отрицания won't, wouldn't, shouldn't, mightn't, которые вносят в сообщение тональности сомнения, неуверенности. При необходимости выразить критику и недовольство коммуниканты прибегают к средствам смягчения неприятного содержания высказывания (will you?, shall we?). Для передачи собственного мнения, самодистанцирования и самопозиционирования в коммуникации чаще используются высказывания с обычными грамматическими операторами глаголов (запросы на подтверждение информации, на сотрудничество, помощь, участие).

\section{Заключение}

Обобщение результатов лингвопрагматического анализа и сопоставление их с выводами, представленными в публикациях коллег-лингвистов, позволили подтвердить гипотезу исследования об узуальном разнообразии реализации моделей разделительного вопросительного высказывания и его дискурсивной многофункциональности в британской традиции межличностного общения. Уточнение вопроса о нормативности структуры РВВ показало вариативность приемов реализации бинарности информативно-прагматических функций. Основная (констатирующая) часть РВВ, если она выражена утверждением или содержит отрицание, передает информацию или размышления говорящего, вопросительный тэг является маркером запроса о подтвержде- нии. Если предикативная часть основы высказывания образована модальным глагольным сказуемым, то она передает оттенки коммуникативной тональности: от высокой степени уверенности до низкой, а вопросительные тэги-модальные глаголы - разные оттенки коммуникативной тональности: от (не)уверенности, (не)определенности до (не)согласия, а также смягченной критики, раздражения (will, won't, can't). Разделительный вопрос, обладая формальной и смысловой контрастностью, отличается особым прагматическим потенциалом. Формальная контрастность утвердительной части и переспроса скрывает интенцию личной заинтересованности и коммуникативной власти говорящего, а также, не нарушив его имиджа, смягчить последствия возможного нарушения персональной дистанции партнера: That's not quite true, is it? In fact you've phoned us twelve times in the last fortnight? Выявленные узуальные варианты построения разделительных вопросов и ассоциируемые с ними прагматические функции и интенции (информационная, этикетная, корректирующая) свидетельствуют о значимости РВВ для английской (британской) традиции межличностного общения, с их помощью происходит коммуникативное дистанцирование, смягчение высказывания в языковых знаках позитивной и негативной вежливости, самопрезентация личности.

К перспективам исследования мы относим проведение коллоструктивного анализа форм разделительного вопроса инструментами корпусной лингвистики с целью выявить семантические признаки коллокаций с определенными грамматическими конструкциями РВВ. В силу того, что синтаксическая структура разделительного вопроса приобретает разнообразные грамматические формы и характеризуется определенным набором прагматических функций, выборка статистически частотных коллокаций для каждого тэга позволит выявить взаимосвязь грамматического, семантического и прагматического компонентов этой речевой конструкции, имеющей особую дискурсивную ценность в британской традиции межличностного общения. 


\section{ПРИМЕЧАНИЯ}

${ }^{1}$ Примеры из корпуса современной британской прозы сопровождаются указанием на автора произведения и страницу: $E H$ - Healey, Emma Elizabeth is Missing. L. : Penguin Random House UK, 2014. 275 p.; $R R$ - Rendell R. Portobello Road. N. Y. : Penguin Random House UK, 2008. 278 p.

${ }^{2}$ В статье приводятся примеры из корпуса устной британской речи BNC2014 (BNC2014 Spoken British National Corpus 2014. URL: https:// cqpweb.lancs.ac.uk/). Каждый пример сопровождается указанием на идентификационный номер респондента, зафиксированный в корпусе, сохраняется графическое отражения скрипта устной речи.

\section{СПИСОК ЛИТЕРАТУРЫ}

Евсикова Е. А., 2017. Разделительный вопрос и обращение как актуализаторы фактора воздействия на адресата в английском диалогическом дискурсе // Вестник Брянского государственного университета. № 3 (33). С. 243-248. URL: http://vestnik-brgu.ru/wp-content/ numbers/v2017_3.pdf (дата обращения: 16.04.2021).

Иванова И.П., Бурлакова В.В., Почепцов Г.Г., 1981. Теоретическая грамматика английского языка. М. : Высш. шк. 285 с.

Ильинова Е. Ю., Кочетова Л. А., 2018. Дискурсивная саморепрезентация личности в англоязычном межличностном общении: корпусный прагмасоциолингвистический анализ // Вестник Волгоградского государственного университета. Серия 2, Языкознание. Т. 17, № 3. C. 35-48. DOI: https:// doi.org/10.15688/jvolsu2.2018.3.4.

Ирисханова О. К., 2009. Речевые акты уклонения: на стыке когнитологии и прагматики // Горизонты современной лингвистики: традиции и новаторство. М. : Яз. слав. культур. С. 684-693.

Историческая динамика дискурсивных практик, 2017 : коллектив. моногр. / науч. ред. Л. А. Кочетова, Е. Ю. Ильинова. Волгоград : Изд-во ВолГУ. $228 \mathrm{c.}$

Карасик В. И., 2017. Языковая пластика общения. Волгоград : Парадигма. 462 с.

Клепикова Т. А., 2017. Коммуникативный статус зависимой пропозиции в свете теории лингвистического метарепрезентирования // Когнитивные исследования языка. № 31. С. 36-46.

Коготкова С. С., 2013. Функции разделительных вопросов в деловом интервью-диалоге // Русистика. № 2. C. 101-105. URL: http://journals. rudn.ru/russian-language-studies/issue/view/ 628 (дата обращения: 26.02.2021).

Кожедуб Н. В., 2017. Коммуникативно-прагматические особенности разделительных вопросов в перекрестном допросе // Вестник Вятского государственного университета. № 3. С. 6265. URL: http://vestnik43.ru/3-2017-vgu.pdf (дата обращения: 16.04.2021).

Ларина Т. В., 2003. 'Privacy', или автономия личности, как важнейший концепт английской культуры // Вестник Российского университета дружбы народов. Серия: Русский и иностранные языки: методика их преподавания. № 1. C. 128-134. URL: https://www.elibrary.ru/item. asp?id=9900661 (дата обращения: 16.04.2021).

Ларина Т. В., 2013. Англичане и русские : язык, культура, коммуникация. М. : Яз. слав. культур. $360 \mathrm{c}$.

Лебедева И. С., 2019. «Разделительный вопрос», или универсальный коммуникативный ход? К истории вопроса // Функционально-когнитивные аспекты актуализации грамматических форм и структур в синхронии и диахронии (на материале английского языка). М. : Моск. гос. лингв. ун-т. С. 267-352.

Леонтович О. А., 2011. Методы коммуникативных исследований. М. : Гнозис. 224 с.

Матвеева Г. Г., Ленец А. В., Петрова Е. И., 2013. Основы прагмалингвистики. М. : Флинта : Наука. 232 с.

Прибыток И. И., 2008. Теоретическая грамматика английского языка. М. : Академия. 382 с.

Селезнева В. В., Евсикова Е. А., Тарвердян А. Ш., 2019. Английский разделительный вопрос как лингвоэкологичный феномен межличностного общения // Научный диалог. № 7. C. 107-123. DOI: 10.24224/2227-1295-2019-7107-123.

Сиротинина О. Б., 2013. Русский язык: система, узус и создаваемые ими риски. Саратов : Изд-во Сарат. ун-та. $116 \mathrm{c.}$

Сорокина Т. С., Мачина О. А., Салькова М. А., Лебедева И. С., 2019. Функционально-когнитивные аспекты актуализации грамматических форм и структур в синхронии и диахронии (на материале английского языка). М. : Моск. гос. лингв. ун-т. 386 с.

Чернявская В. Е., 2017. Методологические возможности дискурсивного анализа в корпусной лингвистике // Вестник Томского государственного университета. Филология. № 50. C. 135-148. DOI: 10.17223/19986645/50/9.

Чернявская В. Е., 2018. Дискурсивный анализ и корпусные методы: необходимое доказательное звено? Объяснительные возможности качественных и количественных подхо- 
дов // Вопросы когнитивной лингвистики. № 2 (55). C. 31-37. DOI: 10.20916/ 1812-32282018-2-31-37.

Algeo J., 1988. The Tag Question in British English: It's Different I'nit? // Sociology. English WorldWide. № 9. P. 171-191.

Baker P., 2006. Using Corpora in Discourse Analysis. L. : Continuum. 198 p.

Baker P., 2012. Acceptable Bias? Using Corpus Linguistics Methods with Critical Discourse Analysis // Critical Discourse Studies. Vol. 9. P. 247-256. URL: http:// www.research.lancs.ac.uk/portal/en/publications/ acceptable-bias(f059d10e-5292-4379-8d0dce729bfe6373)/export.html (date of access: 24.04.2021).

Baker P., Gabrielatos C., Khosravinik M., Krzyzanowski M., McEnery T., Wodak R., 2008. A Useful Methodological Synergy? Combining Critical Discourse Analysis and Corpus Linguistics to Examine Discourse of Refugees and Asylum Seekers in the UK Press // Discourse and Society. Vol. 19(3). P. 273-306. DOI: 10.1177/ 0957926508088962.

Baker P., McEnery A., 2015. Corpora and Discourse Studies: Integrating Discourse and Corpora. Basingstoke : Palgrave Macmillan. 310 p.

Biber D., Johansson S., Leech G., Conrad S. Finegan E., 1999. Longman Grammar of Spoken and Written English. Essex : Pearson Education Limited. 1204 p.

Brezina V., 2018. Statistical Choices in Corpus-Based Discourse Analysis // Corpus Approaches to Discourse/ ed. by Ch. Taylor, A. Marchi. Oxford : Routledge. P. 259-280.

Brown P., Levinson S., 1987. Politeness: Some Universals in Language Usage. Cambridge : Cambridge University Press. 325 p. (Studies in International Sociolinguistics ; 4).

Cameron D., 1997. Dreaming the Dictionary: Keywords and Corpus Linguistics // KeyWords. № 1. P. $35-45$.

Downing A., 2015. English Grammar: A University Course. $3^{\text {rd }}$ ed. N. Y. : Routledge. 652 p.

Dubois B. L., Crouch I., 1975. The Question of Tag Questions in Women's Speech: They Don't Really Use More of Them, Do They? // Language in Society. Vol. 4, № 3. P. 289-294.

English Language: Description, Variation and Context, 2018 / ed. by J. V. Culpeper, P. Kerswill, R. Wodak, T. McEnery, F. Katamba. $2^{\text {nd }}$ ed. L. : Palgrave Macmillan. $686 \mathrm{p}$.

Fox K., 2004. Watching the English. The Hidden Rules of English Behavior. L. : Hodder. 424 p.

Friginal E., Hardy J., 2014. Corpus-Based Sociolinguistics: A Guide for Students. L. ; N. Y. : Routledge. 312 p.
Holmes J., 1983. The Functions of Tag Questions// English Language Research Journal. № 3. P. 40-65.

Kimps D., 2007. Declarative Constant Polarity Tag Questions: A Data-Driven Analysis of Their Form, Meaning and Attitudinal Uses // Journal of Pragmatics. № 39 (2). P. 270-291.

Kimps D., 2018. Tag Questions in Conversation : A Typology of Their Interactional and Stance Meanings. Amsterdam : John Benjamins Publishing Company. $250 \mathrm{p}$.

Lakoff R., 1975. Language and Woman's Place. N. Y. : Harper and Row. 328 p.

Mautner G., 2009. Corpora and Critical Discourse Analysis // Contemporary Approaches to Corpus Linguistics / ed. by P. Baker. L. : Continuum. P. 32-46.

Nässlin Siv.,1984. The English Tag Question: A Study of Sentences Containing Tags of the Type ISN'T IT? Stockholm : Almqvist and Wiksell. 204 p. (Stockholm Studies in English ; 60).

Partington A., 2004. Corpora and Discourse, a Most Congruous Beast // Corpora and Discourse / ed. by A. Partington, J. Morley, P. Bayley. Bern : Peter Lang. P. 11-20.

Partington A., 2010. Modern Diachronic CorpusAssisted Discourse Studies on UK Newspapers: An Overview of the Project // Corpora. Vol. 5, iss. 2. P. 83-108.

Pearson J. C., West R., Turner L. H., 2005. Gender and Communication. N. Y. : McGraw-Hill. 285 p.

Quirk R., Greenbaum S., Leech G., Svartvik J., , 1985. A Comprehensive Grammar of the English Language. L. : Longman. 1779 p.

Stubbs M. 1997. Whorf's Children: Critical Comments on Critical Discourse Analysis // Evolving Models of Language. Clevedon : Multilingual Matters. P. 100-116.

Stubbs M., Gerbig A., 1993. Human and Inhuman Geography: On the Computer-Assisted Analysis of Long Texts // Data, Description, Discourse : Papers on the English Language in Honour of John McH Sinclair on his Sixtieth Birthday / ed. by M. Hoye. L. : Harper Collins. P. 64-85.

Tottie G., Hoffmann S., 2006. Tag Questions in British and American English // Journal of English Linguistics. № 34. P. 283-311. DOI: 10.1177/ 0075424206294369.

Tottie G., Hoffmann S., 2009. Tag Questions in English: The First Century// Journal of English Linguistics. № 37 (2). URL: https://doi.org/10.1177/ 0075424209332962 (date of access: 11.04.2021).

\section{REFERENCES}

Evsikova E.A., 2017. Razdelitelnyy vopros i obrashcheniye kak aktualizatory faktora 
vozdeystviya na adresata $\mathrm{V}$ angliyskom dialogicheskom diskurse [A Tag Question and a Direct Address as Actualizers of Addressee Speech Impact in English Interpersonal Discourse]. Vestnik Bryanskogo gosudarstvennogo universiteta [The Bryansk State University Herald], no. 3 (33), pp. 243-248. URL: http://vestnik-brgu.ru/wpcontent/numbers/v2017 3.pdf (accessed 16 April 2021).

Ivanova I.P., Burlakova V.V., Pocheptsov G.G., 1981. Teoreticheskaya grammatika angliyskogo yazyka [Theory of Modern English Grammar]. Moscow, Vysshaya shkola Publ. 285 p.

Ilyinova E.Yu., Kochetova L.A., 2018. Diskursivnaya samoreprezentatsiya lichnosti v angloyazychnom mezhlichnostnom obshchenii: korpusnyy pragmasotsiolingvisticheskiy analiz [SelfRepresentation in English Spoken Discourse: Corpus-Based Pragmatic-and-Sociolinguistic Approach]. Vestnik Volgogradskogo gosudarstvennogo universiteta. Seriya 2. Yazykoznanie [Science Journal of Volgograd State University. Linguistics], vol. 17, no. 3, pp. 35-48. DOI: https://doi.org/10.15688/ jvolsu2. 2018.3.4.

Iriskhanova O.K., 2009. Rechevye akty ukloneniya: na styke kognitologii i pragmatiki [Speech Acts of Evasion: The Border Line Between Cognitive and Pragmatic Sciences]. Gorizonty sovremennoy lingvistiki: traditsii i novatorstvo [Horizons of Modern Linguistics: Traditions and Innovations]. Moscow, Yazyki slavyanskikh kultur Publ., pp. 684-693.

Kochetova L.A., Ilyinova E.Yu., eds., 2017. Istoricheskaya dinamika diskursivnykh praktik [On Historical Dynamics of Discourse Practice]. Volgograd, Izd-vo VolGU. 228 p.

Karasik V.I., 2017. Yazykovaya plastika obshcheniya [Language Plasticity of Communication]. Volgograd, Paradigma Publ. $462 \mathrm{p}$.

Klepikova T.A., 2017. Kommunikativnyy status zavisimoy propozitsii v svete teorii lingvisticheskogo metareprezentirovaniya [Communicative Status of Dependent Propositions in Linguistic Metarepresentations]. Kognitivnye issledovaniya yazyka [Cognitive Studies of Language], no. 31, pp. 36-46.

Kogotkova S.S., 2013. Funktsii razdelitelnykh voprosov $\mathrm{v}$ delovom intervyu-dialoge [Functions of Tag Questions in Business Interview-Dialogue]. Rusistika [Russian Language Studies], no. 2, pp. 101-105. URL: http://journals.rudn.ru/russian-languagestudies/article/view/10317/9768 (accessed 26 February 2021).
Kozhedub N.V., 2017. Kommunikativno-pragmaticheskie osobennosti razdelitelnykh voprosov $\mathrm{v}$ perekrestnom doprose [Communicative and Pragmatic Peculiarities of Tag Questions in Crossexamination]. Vestnik Vyatskogo gosudarstvennogo universiteta [Herald of Vyatka State University], no. 3, pp. 62-65. URL: http://vestnik43.ru/3-2017-vgu.pdf (accessed 16 April 2021).

Larina T.V., 2003. 'Privacy', ili avtonomiya lichnosti, kak vazhneyshiy kontsept angliyskoy kultury [Privacy, or Autonomy of the Person, As Major Concept of English Culture]. Vestnik Rossiyskogo universiteta druzhby narodov. Seriya: Russkiy i inostrannye yazyki: metodika $i k h$ prepodavaniya [Journal of Peoples' Friendship University of Russia (RUDN University). Russian and Foreign Languages: Methods of Teaching], no. 1, pp. 128-134. URL: https://www.elibrary.ru/item.asp?id=9900661 (accessed 16 April 2021).

Larina T.V., 2013. Anglichane i russkie : yazyk, kultura, kommunikatsiya [English and Russians: Language, Culture, Communication]. Moscow, Yazyki slavyanskikh kultur Publ. $360 \mathrm{p}$.

Lebedeva I.S., 2019. «Razdelitelnyy vopros», ili universalnyy kommunikativnyy khod? K istorii voprosa [Tag Question, or the Universal Code of Communication? On the History of the Topic]. Funktsionalno-kognitivnye aspekty aktualizatsii grammaticheskikh form i struktur $v$ sinkhronii $i$ diakhronii (na materiale angliyskogo yazyka) [Functional-and-Cognitive Aspects of Actualization of Grammatical Forms and Structures in the Focus of Synchrony and Diachrony (On the Bases of the English Language)]. Moscow, Moskovskiy gosudarstvennyy lingvisticheskiy universitet, pp. 267-352.

Leontovich O.A., 2011. Metody kommunikativnykh issledovaniy [Methods of Communication Studies]. Moscow, Gnozis Publ. 224 p.

Matveeva G.G., Lenets A.V., Petrova E.I., 2013. Osnovy pragmalingvistiki [Introduction to Pragmatic Linguistics]. Moscow, Flinta Publ., Nauka Publ. 232 p.

Pribytok I.I., 2008. Teoreticheskaya grammatika angliyskogo yazyka [Theory of English Grammar]. Moscow, Akademiya Publ. 382 p.

Selezneva V.V., Evsikova E.A., Tarverdyan A.Sh., 2019. Angliyskiy razdelitelnyy vopros kak lingvoekologichnyy fenomen mezhlichnostnogo obshcheniya [English Tag Question as LinguoEcological Phenomenon of Interpersonal Communication]. Nauchnyy dialog, no. 7, pp. 107123.DOI: $10.24224 / 2227-1295-2019-7-107-123$.

Sirotinina O.B., 2013. Russkiy yazyk: sistema, uzus $i$ sozdavaemye imi riski [The Russian Language: 
System, Usage and Risks, Produced by Them]. Saratov, Izd-vo Saratovskogo universiteta. $116 \mathrm{p}$.

Sorokina T.S., Machina O.A., Salkova M.A., Lebedeva I.S., 2019. Funkcionalno-kognitivnye aspekty aktualizatsii grammaticheskikh form $i$ struktur v sinkhronii i diakhronii (na materiale angliyskogo yazyka) [Functional-andCognitive Aspects of Actualization of Grammatical Forms and Structures in the Focus of Synchrony and Diachrony (On the Bases of the English Language)]. Moscow, Moskovskiy gosudarstvennyy lingvisticheskiy universitet, $386 \mathrm{p}$.

Chernyavskaya V.E., 2017. Metodologicheskie vozmozhnosti diskursivnogo analiza v korpusnoy lingvistike [Towards Methodological Application ofDiscourse Analysis in Corpus-driven Linguistics]. Vestnik Tomskogo gosudarstvennogo universiteta. Filologiya [Tomsk State University Journal of Philology], no. 50, pp. 135-148. DOI: 10.17223/ 19986645/50/9.

Chernyavskaya V.E., 2018. Diskursivnyy analiz i korpusnye metody: neobkhodimoe dokazatelnoe zveno? Obyyasnitelnye vozmozhnosti kachestvennykh i kolichestvennykh podkhodov [Discourse Analysis and Corpus Approaches: A Missing Evidence-based Link? Towards Qualitative and Quantitative Approaches in Language Studies]. Voprosy kognitivnoy lingvistiki [Issues of Cognitive Linguistics], no. 2 (55), pp. 31-37. DOI: 10.20916/1812-32282018-2-31-37.

Algeo J., 1988. The Tag Question in British English: It's Different I'nit? Sociology. English WorldWide, no. 9, pp. 171-191.

Baker P., 2006. Using Corpora in Discourse Analysis. London, Continuum. 198 p.

Baker P., 2012. Acceptable Bias? Using Corpus Linguistics Methods with Critical DiscourseAnalysis. Critical Discourse Studies, vol. 9, pp. 247-256. URL: http:// www.research.lancs.ac.uk/portal/en/publications/ acceptable-bias(f059d10e-5292-4379-8d0dce729bfe6373)/export.html (accessed 24April 2021).

Baker P., Gabrielatos C., KhosravinikM., Krzyzanowski M., McEnery T., Wodak R., 2008. A Useful Methodological Synergy? Combining Critical Discourse Analysis and Corpus Linguistics to Examine Discourse of Refugees and Asylum Seekers in the UK Press. Discourse and Society, vol. 19 (3), pp. 273-306. DOI: 10.1177/0957926508088962.

Baker P., McEnery A., 2015. Corpora and Discourse Studies: Integrating Discourse and Corpora. Basingstoke, Palgrave Macmillan. 310 p.

Biber D., Johansson S., Leech G., Conrad S. Finegan E., 1999. Longman Grammar of Spoken and Written English. Essex, Pearson Education Limited. 1204p.
Brezina V., 2018. Statistical Choices in Corpus-Based Discourse Analysis. Taylor Ch., Marchi A. Corpus Approaches to Discourse. Oxford, Routledge, pp. 259-280.

Brown P., Levinson S., 1987. Politeness: Some Universals in Language Usage. Cambridge, Cambridge University Press. 325 p. (Studies in International Sociolinguistics; 4).

Cameron D., 1997. Dreaming the Dictionary: Keywords and Corpus Linguistics. KeyWords, no. 1, pp. 35-45.

Downing A., 2015. English Grammar: A University Course. New York, Routledge. 652 p.

Dubois B.L., Crouch I., 1975. The Question of Tag Questions in Women's Speech: They Don't Really Use More of Them, Do They? Language in Society, vol. 4, no. 3, pp. 289-294.

Culpeper J.V., Kerswill P., Wodak R., McEnery T., Katamba F., eds., 2018. English Language: Description, Variation and Context. London, Palgrave Macmillan. $686 \mathrm{p}$.

Fox K., 2004. Watching the English. The Hidden Rules of English Behavior. London, Hodder. $424 \mathrm{p}$.

Friginal E., Hardy J., 2014. Corpus-Based Sociolinguistics: A Guide for Students. London, New York, Routledge. 312 p.

Holmes J., 1983. The Functions of Tag Questions. English Language Research Journal, no. 3, pp. 40-65.

Kimps D., 2007. Declarative Constant Polarity Tag Questions: A Data-Driven Analysis of Their Form, Meaning and Attitudinal Uses. Journal of Pragmatics, no. 39 (2), pp. 270-291.

Kimps D., 2018. Tag Questions in Conversation: A Typology of Their Interactional and Stance Meanings. Amsterdam, John Benjamins Publishing Company. $250 \mathrm{p}$.

Lakoff R.,1975. Language and Woman's Place. New York, Harper and Row. 328 p.

Mautner G., 2009. Corpora and Critical Discourse Analysis. Baker P., ed. Contemporary Approaches to Corpus Linguistics. London, Continuum, pp. $32-46$.

Nässlin Siv.,1984. The English Tag Question: A Study of Sentences Containing Tags of the Type ISN'T IT? Stockholm, Almqvist and Wiksell. 204 p. (Stockholm Studies in English; 60).

Partington A., 2004. Corpora and Discourse, a Most Congruous Beast. Partington A., Morley J., Bayley P., eds. Corpora and Discourse. Bern, Peter Lang, pp.11-20.

Partington A., 2010. Modern Diachronic CorpusAssisted Discourse Studies on UK Newspapers: An Overview of the Project. Corpora, vol. 5, iss. 2, pp. 83-108. 
Pearson J.C., West R., Turner L.H., 2005. Gender and Communication. New York, McGraw-Hill. $285 \mathrm{p}$.

Quirk R., Greenbaum S., Leech G., Svartvik J., 1985. A Comprehensive Grammar of the English Language. London, Longman. 1779 p.

Stubbs M., 1997. Whorf's Children: Critical Comments on Critical Discourse Analysis. Evolving Models of Language. Clevedon, Multilingual Matters, pp. 100-116.

Stubbs M., Gerbig A., 1993. Human and Inhuman Geography: On the Computer-Assisted Analysis of Long Texts. Hoye M., ed. Data, Description, Discourse: Papers on the English Language in Honour of John McH Sinclair on his Sixtieth Birthday. London, Harper Collins, pp. 64-85.

Tottie G., Hoffmann S., 2006. Tag Questions in British and American English. Journal of English Linguistics, no. 34, pp. 283-311. DOI: 10.1177/ 0075424206294369.

Tottie G., Hoffmann S., 2009. Tag Questions in English: The First Century. Journal of English Linguistics, no. 37 (2). URL: https://doi.org/10.1177/ 0075424209332962 (accessed 11 April 2021).

\section{Information About the Authors}

Larisa A. Kochetova, Doctor of Sciences (Philology), Associate Professor, Head of the Department of English Philology, Volgograd State University, Prosp. Universitetsky, 100, 400062 Volgograd, Russia, kochetova@volsu.ru, english_philology@volsu.ru, https://orcid.org/0000-0002-5278-7373

Elena Yu. Ilyinova, Doctor of Sciences (Philology), Professor, Department of English Philology, Volgograd State University, Prosp. Universitetsky, 100, 400062 Volgograd, Russia, ilynov@volsu.ru, english_philology@volsu.ru, https://orcid.org/0000-0002-3310-4020

Tatiana A. Klepikova, Doctor of Sciences (Philology), Associate Professor, Professor, Department of English Language Theory and Translation Studies, Saint Petersburg State University of Economics, Sadovaya St, 21, 191023 Saint Petersburg, Russia, tklepikova@gmail.com, https://orcid.org/0000-0001-9745-5201

\section{Информация об авторах}

Лариса Анатольевна Кочетова, доктор филологических наук, доцент, заведующая кафедрой английской филологии, Волгоградский государственный университет, просп. Университетский, 100, 400062 г. Волгоград, Россия, kochetova@volsu.ru, english_philology@volsu.ru, https://orcid.org/0000-0002-5278-7373

Елена Юрьевна Ильинова, доктор филологических наук, профессор кафедры английской филологии, Волгоградский государственный университет, просп. Университетский, 100, 400062 г. Волгоград, Россия, ilynov@volsu.ru, english_philology@volsu.ru, https://orcid.org/0000-0002-3310-4020

Татьяна Альбертовна Клепикова, доктор филологических наук, доцент, профессор кафедры теории и практики английского языка и перевода, Санкт-Петербургский государственный экономический университет, ул. Садовая, 21, 191023 г. Санкт-Петербург, Россия, tklepikova@gmail.com, https://orcid.org/0000-0001-9745-5201 